\title{
Research Progress of Gas Sensor Based on Graphene and Its Derivatives: A Review
}

\author{
Wenchao Tian, Xiaohan Liu * and Wenbo Yu ${ }^{(D)}$ \\ School of Electro-Mechanical Engineering, Xidian University, Number 2 Taibai South Road, Xi'an 710071, China; \\ wctian@xidian.edu.cn (W.T.); wenbo.yu.albert@outlook.com (W.Y.) \\ * Correspondence: xiaohanliu@stu.xidian.edu.cn; Tel.: +86-156-9141-9367
}

Received: 21 May 2018; Accepted: 4 July 2018; Published: 11 July 2018

Featured Application: gas sensors based on graphene and its derivatives have brilliant development prospects on innovating composite material and designing appropriate structure.

\begin{abstract}
Gas sensors are devices that convert a gas volume fraction into electrical signals, and they are widely used in many fields such as environmental monitoring. Graphene is a new type of two-dimensional crystal material that has many excellent properties including large specific surface area, high conductivity, and high Young's modulus. These features make it ideally suitable for application for gas sensors. In this paper, the main characteristics of gas sensor are firstly introduced, followed by the preparation methods and properties of graphene. In addition, the development process and the state of graphene gas sensors are introduced emphatically in terms of structure and performance of the sensor. The emergence of new candidates including graphene, polymer and metal/metal oxide composite enhances the performance of gas detection significantly. Finally, the clear direction of graphene gas sensors for the future is provided according to the latest research results and trends. It provides direction and ideas for future research.
\end{abstract}

Keywords: graphene; gas sensor; sensitive; response time; composite; synthesis

\section{Introduction}

With the improvement of industry, living standards and the emphasis on the environment, the detection of toxic and hazardous gases is facing higher challenges. In addition, sensors sensing the surrounding gas environment play an important role in this field. Gas sensors are devices that convert the gas volume fraction into corresponding electrical signal [1]. They are of crucial importance in environmental monitoring, industrial chemical processing, public safety, agriculture and medicine [2]. With the development of science and technology, the development of gas sensors towards high sensitivity, high selectivity, fast response, low cost, low power consumption, stability and portability has led to the search for new and superior gas-sensing materials [3].

Metal oxide semiconductor (MOS) gas sensors are the most wildly used gas sensors in the world for production and use due to its high sensitivity and fast response time [4]. The sensing mechanism of the MOS gas sensors is attributed to changes of electric charge carriers caused by oxidation or reduction reactions occurring at the surface of the metal oxide [5]. However, they still have the disadvantages of short life, poor selectivity and high operating temperature. Sensitivity is not sufficient for the application of precision measurement. The key indicator of material gas sensitivity is the specific surface area, which is the total surface area of a material per unit of mass [6]. The large specific surface area of nanomaterials facilitates the adsorption of gas molecules, thereby enhancing the sensitivity of gas detection. Theoretical and experimental results showed that [7] graphene and its derivatives, such as graphene oxide (GO) and reduced graphene oxide (rGO), exhibit large specific surface area, 
excellent conductivity, and easy adsorption of gas molecules, and the surface can easily be modified by functional groups, so it has good gas sensing properties.

Graphene, a monolayer of graphite sheet consisting of $\mathrm{sp}^{2}$ hybridized carbon atoms covalently bonded to three other atoms which was first isolated by Geim and Novoselov using micro-mechanical peeling of graphite in 2004, so they won the 2010 Nobel Prize in Physics [8]. Graphene is the thinnest and highest strength material in nature at present and has the advantages of strong electric conductivity and heat conductivity, and is almost transparent and dense, thus attracts people's attention [9].

Nowadays, there are many studies about graphene gas sensors focused on the performance improvement in the field of composite materials, computational chemistry and Micro-Electro-Mechanical System (MEMS). Considering the practical application of graphene gas sensor, we need to find the most potential direction. In this article, the development process and the state of art of graphene gas sensors are introduced. The direction of graphene gas sensors for the future is also provided. The review provides important reference for follow-up research work.

\section{Gas Sensor}

\subsection{Key Parameters of Gas Sensor}

Gas sensors are the crucial components to detect the type and concentration of gas. The components can transform gas composition, gas concentration and other information from non-electricity to electricity to achieve the measurement of gas [10].

The key parameters of gas sensor measuring performance include the following aspects [11]:

\section{Sensitivity}

The sensitivity represents the change degree in response [12]. Sensitivity is usually expressed as the ratio of the resistance of the gas sensor in the gas under test to the resistance in normal air (or $N_{2}$ ) and is denoted by $S\left(S=R_{g} / R_{a}\right.$, where $R_{g}$ means the resistance of gas sensing materials at a certain concentration of target gas, while $R_{a}$ means the resistance of gas sensing materials at ambient air atmosphere).

\section{Selectivity}

Selectivity is the ability of gas sensors to differentiate gas species in the presence of multiple gases. The sensitivity of a good sensor to target gas should be higher than that of the interfering gas Response time $\left(t_{\text {res }}\right) /$ Recovery Time $\left(t_{\text {res }}\right)$.

The response time and recovery time reflect the response and desorb speed of the gas sensor to the detected gas. The faster is the speed, the better is the performance. When the gas-sensitive material is in contact with the gas to be measured or the gas concentration changes, it takes a certain time for the material resistance to change and reach a steady state. We define the response time, expressed as $t_{\text {res }}$ as the time it takes for the resistance to reach $90 \%$ change at this concentration when the sensor contacts the detected gas. Similarly, the recovery time is defined and expressed as $t_{\text {rec}}$.

\section{Stability}

Stability is the ability of gas sensors to maintain the same output characteristics over a specified period when the measured gas concentration remains unchanged but other conditions change. If the fluctuation is fierce, the accurate information of the detected gas cannot be reflected.

\section{Repeatability}

Repeatability is the degree to which test results are consistent when gas sensors are continuously tested in the same test environment. Repeatability can affect the working life of the sensor. 
5. Limit of detection (LOD)

The LOD is the minimum gas concentration that gas sensors can detect. The concentration requirements of the detection limit will be different for different application areas. LOD is usually defined on the basis of signal to noise ratio $(\mathrm{S} / \mathrm{N})$, that is, the signal measured by the low level sample is compared with the signal measured by the blank sample to calculate the minimum concentration that can be reliably detected. The detection limit is generally determined by a $\mathrm{S} / \mathrm{N}$ of 3:1.

6. Working temperature

The working temperature is the temperature that can gives the gas sensor its highest sensitivity. The adsorption and desorption rate of gas depends on the reaction temperature, and different sensing characteristics are obtained at different operating temperatures.

\subsection{Graphene Gas Sensors with Different Working Principles}

Graphene has excellent electron mobility and large specific surface area, and exhibits good gas sensing properties. Graphene material as a p-type semiconductor contains many holes [13], and has pull electron effect in gas atmosphere. After gas molecules are adsorbed by graphene, the gas molecules will undergo weak hybridization and coupling with the electron on the surface, and the fermi level to move up and down in small increments. The state of electron doping or hole doping will change the fermi level, thus lead to changes in graphene conductivity. Thus, graphene is particularly sensitive to the detection of adsorbed small molecule gases. The donor and acceptor depend on the relative position of the electron energy level orbit of the system. If the valence band of the adsorbed gas is higher than the fermi surface of graphene, the gas molecules act as donor for the electrons; on the contrary, if the valence band is lower than the fermi surface of graphene, the gas molecules act as acceptor.

The working principles of graphene sensors mainly include the following: resistive, Field Effect Transistor (FET), quality sensitive and MEMS.

\subsubsection{Resistive Gas Sensor}

Most gas sensors reported so far are operated in a resistive mode. The gas concentration is analyzed by direct test sensor with the change of resistance under the interaction with the detection gas [14]. Its structure is shown in Figure 1. The substrate is made of insulating material such as ceramic or silicon dioxide, and the graphene material or various graphene composite materials is coated or grown on the surface of the substrate as gas-sensing materials. The electrodes are drawn at both ends of the gas-sensitive material. When the detected gas and gas-sensitive materials in contact, gas molecules adsorbed on the surface of gas-sensitive materials resulting in resistance changes. The gas can be measured qualitatively and quantitatively according to the change of resistance [15].

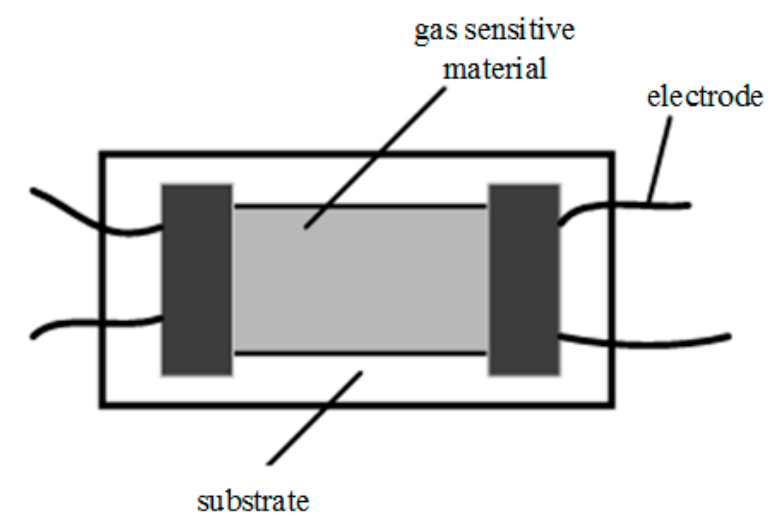

Figure 1. Resistive gas sensor structure. 


\subsubsection{FET Gas Sensor}

FET gas sensors detect the gas using the dependency of the current on the field strength. FET devices have three electrodes: the source (S), the gate $(G)$, and the drain (D). The source-drain current $\left(\mathrm{I}_{\mathrm{DS}}\right)$ of the FET has a significant relationship with the gate voltage $\left(\mathrm{V}_{\mathrm{g}}\right)$, and there is a significant change in the gas detection. As for p-type semiconductor, an induced charge is generated in the semiconductor near the gate insulating layer to form a conductive channel under the influence of a negative gate bias $\left(\mathrm{V}_{\mathrm{G}}\right)$ [16]. Graphene exhibits a strong field effect [17]. Thus, graphene based FET sensors have become promising sensors. When a gas molecule is adsorbed on the surface of graphene, the local concentration of carriers changes, resulting in a change in $\mathrm{I}_{\mathrm{DS}}[18]$.

\subsubsection{Quality Sensitive Gas Sensor}

The principle of quality sensitive sensor is that the operating frequency of the device changes with the type and concentration of the gas being detected. The change in frequency is proportional to the mass of gas molecules absorbed [19]. Quality sensitive sensors can be divided into surface acoustic wave (SAW) sensors and quartz crystal microbalance (QCM) sensors. Among them, the SAW gas sensors are more common than the QCW gas sensor. The SAW device is composed of a delay line, and graphene film is wrapped on the signal propagation path of the delay line to adsorb the gas molecules. When the gas concentration and species change in the sensitive region, the information of the sound speed and phase at the delay line will change, and leads to the change of electrical signal.

\subsubsection{MEMS Gas Sensor}

To achieve device miniaturization, low power consumption, fast sensor response, and mass production, micro-electromechanical systems based on new semiconductor processes are used in sensor technology. Lee et al. (2017), from Electronics and Telecommunications Research Institute, prepared a MEMS-based $\mathrm{NO}_{2}$ gas sensor $\mathrm{ZnO}$ nano-rods for the Internet of Things (IoT) monitoring system. The sensor has a sensitivity of 0.36 at $0.5 \mathrm{ppm}$ and a power consumption of $15 \mathrm{~mW}$, showing that it can be used in IoT operating at low power [20]. IoT refers to a vast network of information sensing devices such as radio frequency identification devices, infrared sensors, global positioning systems, laser scanners, gas sensors and other devices combined with the Internet. All items connect as a network, and are easy to identify and manage. The new type gas sensors with good sensitivity and low power micro-heater are more practical in IoT than commercial semiconductor gas sensors considering they need heaters with a power of a few hundreds of milliwatts. To achieve device miniaturization, low power consumption, fast sensor response, and mass production, microelectromechanical systems based on new semiconductor processes are used in sensor technology. Gas sensor arrays and flexible gas sensors with superior performance have been prepared [21].

\section{Preparation and Properties of Graphene}

\subsection{Preparation of Graphene}

Micro-mechanical exfoliation is the earliest method for preparing graphene. Andre Geim et al. (2004), from the University of Manchester, obtained the single-layer, high-purity graphene for the first time by repeatedly peeling flakes of graphite off the platform which were fixed onto a silicon dioxide/silicon $\left(\mathrm{SiO}_{2} / \mathrm{Si}\right)$ substrate using scotch tapes [22]. Single-layer graphite can be torn down by pasting the graphite tape repeatedly due to the weak van der Waals forces between graphite sheets.

With the progress of research on graphene, it is found that the production of graphene by mechanical peeling is low in yield, poor in repeatability and difficult to precisely control, so it can only be used in laboratories [23]. To make graphene practical, how to rapidly prepare large-area, high-quality monolayers and few layers of graphene films has become a subject of extensive research. Thus far, several fabrication routes for the production of graphene have been established, such as chemical vapor deposition, silicon carbide epitaxial growth method, oxidation-reduction method, etc. 
Chemical vapor deposition (CVD) method is controllable and can be widely used in the preparation of graphene to increase the contact area with the test substance, and thus easier to use in the field of sensors [24,25]. In high-temperature decomposable gases $\left(\mathrm{CH}_{4}\right.$ and $\left.\mathrm{C}_{2} \mathrm{H}_{2}\right)$, carbon atoms are deposited on the surface of the substrate (such as $\mathrm{Cu}, \mathrm{Pt}, \mathrm{Ni}$, $\mathrm{Ru}$ and $\mathrm{Ir}$ ) by high-temperature annealing to form single-layer graphene [26-31]. In 2006, Somani et al. first made about 35 layers of graphene using thermal chemical vapor deposition [32]. This method has the advantages of low cost, simple steps, potential for mass production and environmental friendliness, providing a completely new direction for future research. Early in 2009, the B.H. Hong research group at Sungkyunkwan University in Korea used a silicon wafer deposited with a polycrystalline Ni film as a substrate to prepare large-area and small-layer graphene, and graphene successfully transferred from the substrate, which set off the upsurge of CVD graphene preparation [33]. Subsequently, Xuesong Li et al. from the University of Texas at Austin grew graphene on copper foil by a carbon atom chemical vapor deposition method at a temperature of $1000{ }^{\circ} \mathrm{C}$ using a mixed atmosphere of methane and hydrogen $\left(\mathrm{H}_{2}\right)$, as shown in Figure 2 [34]. The CVD method is considered to be the most promising method for the preparation of high quality, large area graphene, but there are still some disadvantages: high cost; complex production process; breakage, wrinkle and pollution of graphene and material waste during transfer; and inability to control the layer number of graphene produced due to the uncontrollable carbon source.

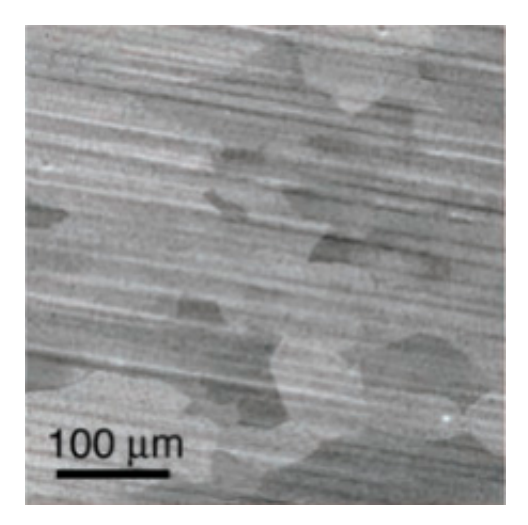

Figure 2. SEM image of graphene on a copper foil with a growth time of $30 \mathrm{~min}$ [34].

Epitaxial growth refers to the growth of a layer of monocrystalline layer with the same orientation as the substrate on a single crystal substrate, as if the original crystal had been extended outward [35]. The raw material used for epitaxial growth was silicon carbide ( $\mathrm{SiC}$ ). The crystal was heated at $1200 \sim 1600{ }^{\circ} \mathrm{C}$, Si atoms evaporate and C atoms remained on the surface, leading to the formation of graphene. Substrate-based epitaxial graphene can be obtained in this way [36]. Berger et al. (2004), from Georgia Institute of Technology, produced a graphene thin layer have similar area as the original $\mathrm{SiC}$ on the (0001) crystal plane by heating large area single crystal SiC to high [37]. The epitaxial growth method is highly attractive for the preparation of high-quality graphene. However, there are still some problems in controlling the number of graphene layers and the repeated preparation of large-area, and researchers need to continue deep research.

The oxidation-reduction method is currently the most widely applied way to achieve large-scale industrial preparation of graphene. The raw materials used in this method are cheap and the preparation process is simple. The method firstly prepares the graphene oxide, which is easier to prepare, and then removes the oxygen-containing groups on the surface of the graphene oxide by thermal reduction or redox reaction [38]. There are three dominant methods preparing GO: Brodie method, Staudenmaier method and Hummers method [39-41]. At present, the wildly used method is the Hummers method due to its mild reaction conditions, little environment pollution, simple and safe operation and less time-consuming, which is the result of more than sixty years of research by 
Hummers et al. The oxidant is a mixture of potassium permanganate and concentrated sulfuric acid. Although the oxidation-reduction method can produce a large amount of graphene at a relatively low cost, the original structure of graphene cannot be completely recovered even after being reduced by a strong reducing agent. Its electronic structure and crystal integrity have been seriously damaged, limiting its application in certain areas such as microelectronics.

Above all, methods and characteristics of preparing graphene are summarized in Table 1 , as shown below.

Table 1. Different methods for graphene synthesis.

\begin{tabular}{ccccc}
\hline Method & Carbon Source & Substrate & Temperature $\left({ }^{\circ} \mathbf{C}\right)$ & Reference \\
\hline Micro-mechanical exfoliation & graphite & $\mathrm{SiO}_{2} / \mathrm{Si}$ & Room temperature & {$[13]$} \\
Chemical Vapor Deposition & $\mathrm{CH}_{4}, \mathrm{C}_{2} \mathrm{H}_{2}$ & $\mathrm{Cu}, \mathrm{Pt}, \mathrm{Ni}, \mathrm{Ru}, \mathrm{Ir}$ & $>1000$ & {$[15-23]$} \\
Epitaxial growth & $\mathrm{SiC}$ & $\mathrm{SiC}$ & $1200 \sim 1600$ & {$[24]$} \\
The oxidation-reduction method & graphite & - & $<500$ & {$[27]$} \\
\hline
\end{tabular}

\subsection{The Property of Graphene}

Graphene, a single, one-atom-thick sheet of carbon atoms arranged in a honeycomb lattice and the two-dimensional building block for carbon materials, as shown in Figure 3. It has attracted great interest for a wide range of applications. It is also the thinnest material in the world [42]. The thickness of graphene is about $0.335 \mathrm{~nm}$, the bond length is $0.142 \mathrm{~nm}$, the bond angle is $120^{\circ}$.

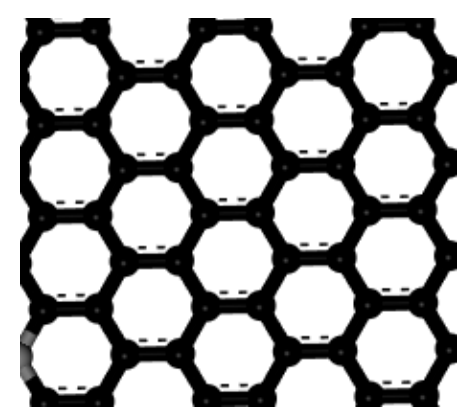

Figure 3. Ideal monolayer graphene structure diagram.

The unique structure of graphene determines its unique properties. Graphene has high strength, excellent electrical conductivity and high thermal conductivity, and quantum Hall effect can be observed at normal temperature [43]. It also has a huge surface area, good adsorption and transmission, and optical absorption of exactly $\pi \alpha \approx 2.3 \%$ (in the infrared limit, where $\alpha$ is the fine structure constant), and is almost transparent [44]. The strong interaction between single carbon-carbon bonds leads to its high mechanical strength, the Young's modulus of graphene is up to 1 Tera Pascal (TPa), about five times that of steel [45], and its breaking strength is up to 130 GPa [46].

Graphene has excellent electrical conductivity. The carrier velocity in graphene reaches $1 / 300$ of the speed of light, far exceeding the movement speed of the carrier in the general conductor [47]. Conductivity is up to $106 \mathrm{~S} / \mathrm{m}$ [48]. In view of the above advantages, graphene is expected to become the core material of the new generation of electronic components in the future.

Graphene also has excellent thermal conductivity. The thermal conductivity of graphene at room temperature is up to $5300 \mathrm{~W} / \mathrm{m} \cdot \mathrm{K}$, which is higher than that of diamond $(2000 \mathrm{~W} /(\mathrm{m} \cdot \mathrm{K}))$ and carbon nanotube $(3500 \mathrm{~W} /(\mathrm{m} \cdot \mathrm{K}))$ [49]. Graphene is the material with the highest thermal conductivity known at present. It has a good application prospect in the field of integrated circuits.

Graphene has huge surface area. The theoretical calculation showed that the surface area of the monolayer graphene was $2630 \mathrm{~m}^{2} / \mathrm{g}$, three times as much as activated carbon [50]. The transmittance of monolayer graphene is $97.7 \%$, almost transparent [51]. Graphene has an important application 
prospect in different fields due to its excellent properties, such as nanomaterials, transparent conductive films, composite materials and sensors [52].

The study of the presence of graphene and its derivatives in aqueous environments is critical to the stability of graphene. Jiang et al. from Washington University in St. Louis studied aqueous aggregation processes of the GO and crumpled GOs (CGO, with different degrees of thermal reduction, and thus oxygen functionality) [53]. The results showed that the more oxidized CGO materials (with more functional groups such as carboxyl and phenolic) are relatively more stable in water. They also studied the interactions of GO and CGO with natural organic matter (NOM) in aquatic environments. The presence of NOM was proven to considerably increase the critical coagulation concentrations (CCC) for all GO materials evaluated, and the effect on CGO was more obvious. The stability is primarily due to enhanced steric repulsion via adsorbed NOM [54]. The research by Jiang et al. provides new information of $\mathrm{GO}$ behavior in water and leads people to conduct more in-depth research.

\section{Graphene Gas Sensor}

\subsection{Gas Sensors Based on Pristine Graphene}

In 2007, Schedin et al. used mechanically stripped graphene for the detection of individual gas molecules [55]. In the experiment, the response of graphene to $1 \mathrm{ppm}$ ammonia $\left(\mathrm{NH}_{3}\right)$, carbon monoxide (CO), nitric oxide (NO) and water vapor was measured and the change of resistance was recorded. Figure 4 shows that the resistance of graphene increases after access $\mathrm{NH}_{3}$ and $\mathrm{CO}$. The electron transferred to the graphene material as these two gas molecules adsorbed on the surface of graphene, resulting in reduced conductivity, which increased resistance. The opposite happened after access to water vapor and nitrogen dioxide $\left(\mathrm{NO}_{2}\right)$.

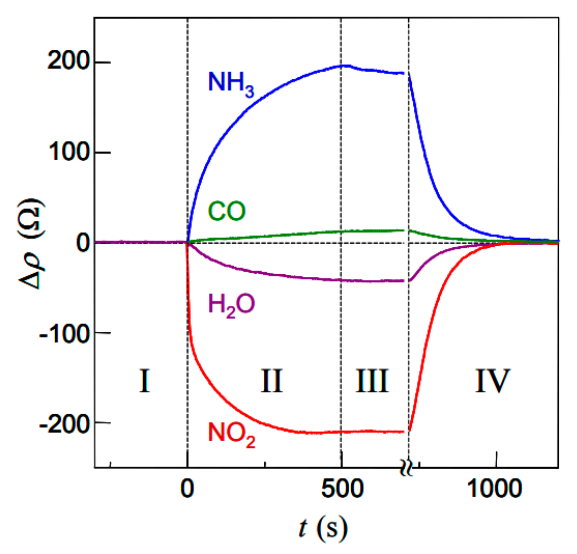

Figure 4. Chemical sensitivity of grapheme [55].

In 2012, Hwang et al. from Yonsei University studied the response of graphene to $\mathrm{NH}_{3}$ with different layer number and length-to-width $(\mathrm{L} / \mathrm{w})$ ratio [56]. The graphene was prepared from highly oriented pyrolytic graphite (HOPG) through mechanical cleavage. Figure 5a shows the different layers of graphene have similar responses to $\mathrm{NH}_{3}$, indicating that the graphene layer (mono-, bi- and tri-layer) has no obvious influence on the sensitivity of gas sensing. Figure $5 b$ indicats that the response time and response intensity obviously changes with the change of $\mathrm{L} / \mathrm{w}$. To sum up, the key factor that affects the sensing of $\mathrm{NH}_{3}$ by graphene is the aspect ratio rather than the layers. 

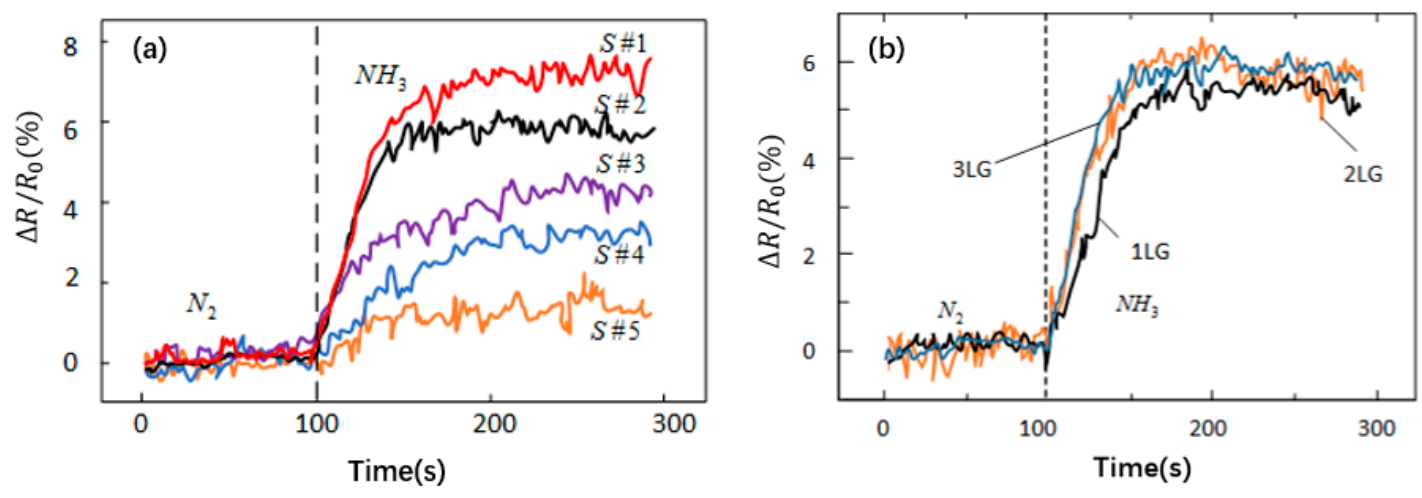

Figure 5. (a) Comparison of the response of monolayer, double and triple layer graphene to $\mathrm{NH}_{3}$ with a flow rate of $200 \mathrm{~mL} / \mathrm{min}$; and (b) The change in response due to $\mathrm{L} / \mathrm{w}$ ratio and surface area of graphene with $\mathrm{NH}_{3}$ flowing at $200 \mathrm{~mL} / \mathrm{min}$ [56].

The micro-mechanical exfoliation method is inefficient, time-consuming, and cannot meet the requirements of wholesale industrialization. Chemical vapor deposition can fill this gap and achieve relatively large area preparation of high quality graphene. In 2011, Hung et al. reported that the surface resistance of monolayer graphene changes significantly after the adsorption of $\mathrm{O}_{2}$ molecules due to the p-type doping of $\mathrm{O}_{2}$ molecules to graphene. The detection limit of the simple $\mathrm{O}_{2}$ sensor was $1.25 \%$ in volume ratio [57]. Chen et al. from University of Wisconsin-Milwaukee prepared patterned vertical graphene nanosheets using plasma-enhanced chemical vapor deposition. The conductivity decreased in $\mathrm{NH}_{3}$ atmosphere, and increased in $\mathrm{NO}_{2}$ atmosphere [58]. In 2012, Fazel Yavari et al. from Rensselear Polytechnic Institute detected trace amounts of $\mathrm{NO}_{2}$ and $\mathrm{NH}_{3}$ in air at room temperature and atmospheric pressure using graphene films synthesized by CVD [59]. The LOD were 100 parts-per-billion (ppb) for $\mathrm{NO}_{2}$ and $500 \mathrm{ppb}$ for $\mathrm{NH}_{3}$, which were markedly superior to commercially available $\mathrm{NO}_{2}$ and $\mathrm{NH}_{3}$ detectors. In 2015, Dutta D. et al. from Jadavpur University prepared a graphene based gas sensor with two Pd electrodes for sensing $\mathrm{H}_{2}$ in air [60]. The lowest response and recovery times obtained in this study were $11.8 \mathrm{~s}$ and $23.6 \mathrm{~s}$, respectively, at $130{ }^{\circ} \mathrm{C}$ in air ambient with $\mathrm{Pd} /$ graphene/Pd planar sensor device.

In 2016, 3D graphene flowers (GF) cluster patterns were successfully prepared by Shuanglong Feng et al. from Nanyang Technological University by inexpensive homebuilt microwave plasma-enhanced chemical vapor deposition (MPCVD) [61]. The GF sensor achieved a high response of $1411 \%$ to $10 \mathrm{ppm} \mathrm{NO}$ and a response of $101 \%$ to $200 \mathrm{ppb} \mathrm{NO}_{2}$. Furthermore, the sensor achieved a theoretical LOD of $785 \mathrm{ppt}$. The sensor also had great recovery characteristic that it took as little as $2 \mathrm{~s}$ to reach $90 \%$ signal recovery and only $20 \mathrm{~s}$ to achieve $100 \%$ recovery.

Small size wearable electronic devices are a major trend in the development of science and technology, and demands for scalable and flexible electronics are increasing. In 2016, Junyeong Yun et al. from Korea University adhered stretchable patterned graphene gas sensor driven by integrated micro-super capacitor (MSC) array on the same deformable substrate, as shown in Figure 6a [62]. The sensor used a stretchable micro-capacitor as a substrate; patterned graphene was placed thereon as a gas-sensitive material. The sensor worked without electricity; was soft, wearable, and small; and performed well, thus having broad application prospects.

In 2017, Ricciardella F from Delft University of Technology prepared the graphene sensing layer by chemical vapor deposition on pre-patterned catalyst and then it was eased onto the underlying $\mathrm{SiO}_{2}$ through a completely transfer-free process [63]. The gas sensing materials had different line width: 5 and $10 \mu \mathrm{m}$. The latter one, having a sensing area reduced by half with respect to the former one, showed a higher sensitivity upon exposure towards both gases, indicating that the sensitivity can be modulated by varying the geometry of the device exposure area. Yanyan Wang et al. from Jiangsu University proposed a vertical responsive gas sensor based on three-dimensional porous graphene 
ultrathin film, as shown in Figure 7 [64]. Different from the flat transportation response, the current in the structure flowed in a direction perpendicular to the graphene film, which avoided the impediment to carriers due to the graphene's adhesion to gas molecules in the plane. The response of the gas sensor to 50 ppm dimethyl methylphosphonate (DMMP) molecule can be over $10 \%$.
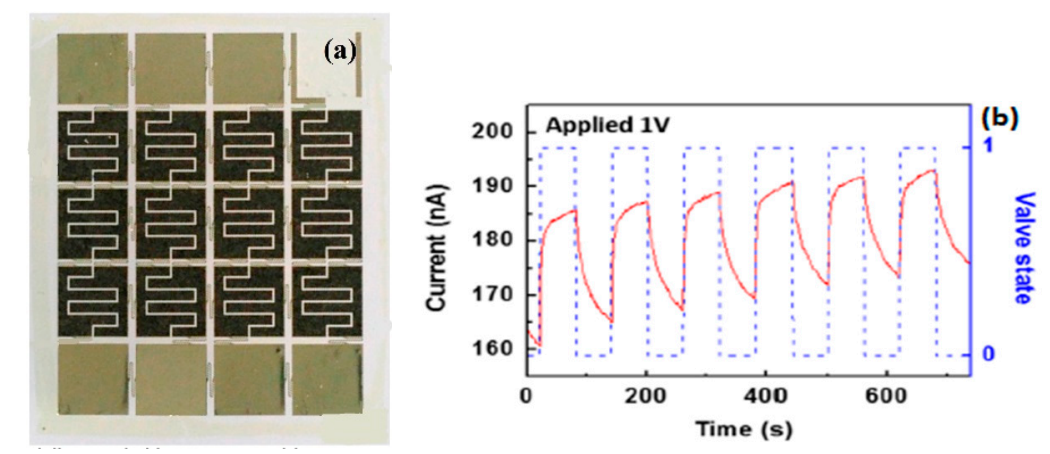

Figure 6. (a) Design concept of biaxially stretchable patterned-graphene sensor integrated with a MSC array; and (b) Current flow, induced by periodic exposure of $200 \mathrm{ppm} \mathrm{NO}_{2}$, through the graphene sensor operated by an external power supply of $1 \mathrm{~V}$ [62].

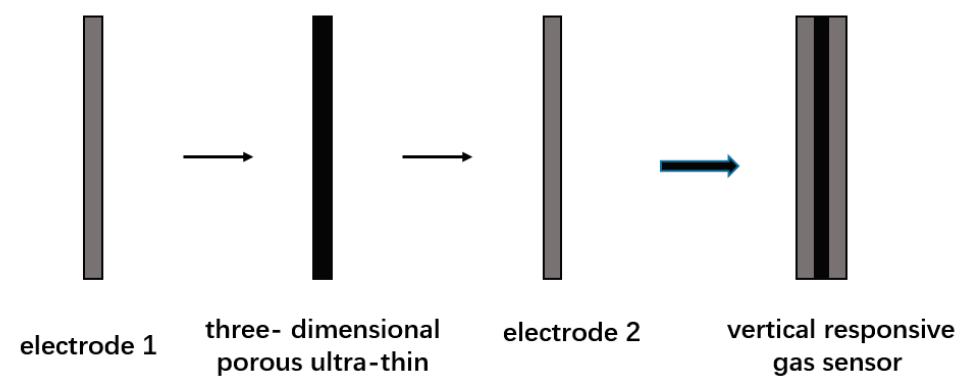

Figure 7. Vertical responsive gas sensor based on 3D porous graphene ultrathin film [64].

In 2017, Wei Wei et al. from Key Laboratory of Optoelectronic Technology \& Systems, Chongqing University proposed a graphene-based long-period fiber grating surface plasmon resonance (LPFG SPR) sensor for high-sensitivity gas sensing and its preparation process, as shown in Figure 8 [65]. A monolayer of graphene was coated onto the Ag film surface of the LPFG-SPR sensor, which increased the intensity of the evanescent field on the surface of the fiber, thereby enhancing the interaction between the SPR wave and molecules. Such features significantly improved the sensitivity of the sensor. The experimental results demonstrated that the sensitivity of the graphene-based LPFG SPR sensor can reach $0.344 \mathrm{~nm} \%^{-1}$ for methane, which was improved 2.96 and 1.31 times with respect to the traditional LPFG sensor and Ag-coated LPFG SPR sensor, respectively.

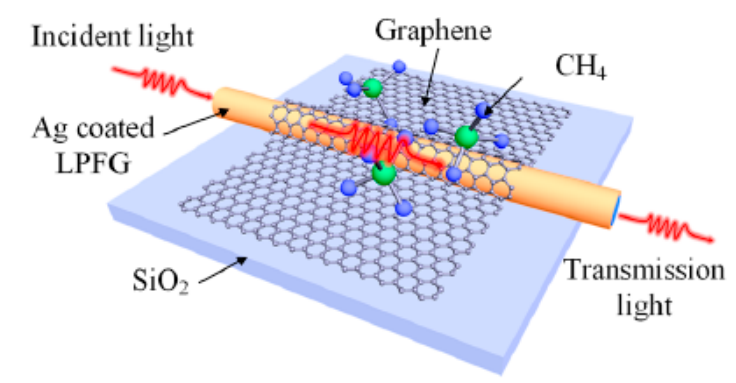

Figure 8. Schematic of the graphene-based LPFG SPR sensor [65]. 
In 2017, Jong-Hyun Kim et al. from University of Utah presented $\mathrm{NH}_{3}$ sensing with ultra-low energy consumption for fast recovery and a graphene sheet based on a suspended micro-heater, as shown in Figure 9 [66]. The silicon micro-heater periodically heated the sensor at a frequency of $1 \mathrm{~Hz}$, which increased the sensor's response time, recovery time, and sensitivity. The sensor showed rapid recovery through heating of the silicon heater. As the temperature increased, the desorption gradually increased by reducing hydrogen bonding. The new oscillation method of heating improved the sensitivity to $0.049\left(\Delta \mathrm{R} / \mathrm{R}_{0}\right)$ measured at a flow rate of $18.8 \mathrm{sccm} \mathrm{NH} \mathrm{N}_{3}(\mathrm{~g})$ for $70 \mathrm{~s}$. The experimental tests showed that a $60 \%$ duty cycle does not sacrifice sensitivity or recovery, while dropping the total power consumption from $1.76 \mathrm{~mW}$ to $1.05 \mathrm{~mW}$.

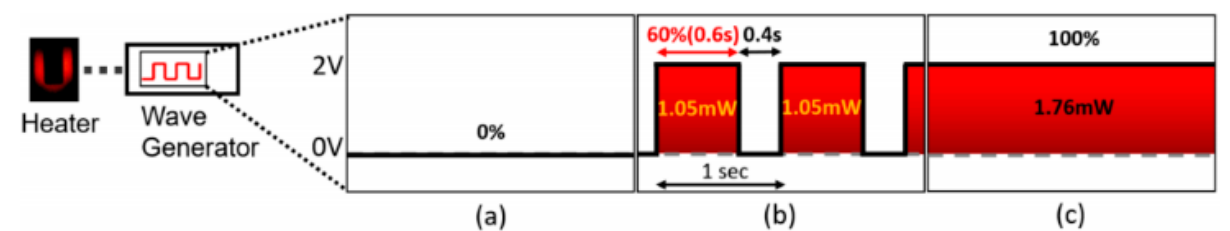

Figure 9. Schematic view of connection with microheater and power wave generator: (a) $0 \%$ duty cycle means non-heating; (b) 60\% duty cycle of oscillation with $2 \mathrm{~V}$ shows $1.05 \mathrm{~mW}$ of energy consumption; and (c) full duty cycle (continuous heating) generates $1.76 \mathrm{~mW}$ of energy consumption [66].

It is observed that the pristine graphene has rapid response and low detection limit on $\mathrm{NO}_{2}, \mathrm{NH}_{3}$ and some organic gas, and even single atom changes can be detected. However, the sensitivity is not high, and it must be accurately detected by the instrument to have obvious changes. There are a few structures of gas sensor being proposed, such as wearable gas sensor, LPFG-SPR sensor, gas sensor based on micro-heater and so on, which brings some limitations to the application of graphene in the field of gas sensing. Above all, shortening the adsorption process is difficult and this is also one direction to enhance gas sensor performance in the future.

\subsection{Gas Sensors Based on Defective and Functionalized Graphene Materials}

In 2007, Yonghui Zhang et al. from Lanzhou University simulated the adsorption effect of graphene, boron-doped graphene, nitrogen-doped graphene and defective graphene on different gas molecules, including $\mathrm{CO}, \mathrm{NO}, \mathrm{NO}_{2}$ and $\mathrm{NH}_{3}$, by first principle calculation [67]. The results showed that graphene had weak adsorption capacity for $\mathrm{CO}$ and $\mathrm{NH}_{3}$, and better adsorption effect for $\mathrm{NO}$ and $\mathrm{NO}_{2}$. Boron doping seemed to enhance the interaction between graphene and $\mathrm{NO}, \mathrm{NO}_{2}$ or $\mathrm{NH}_{3}$. Defective graphene had strong interactions with $\mathrm{CO}, \mathrm{NO}$ and $\mathrm{NO}_{2}$, but weak interacts with $\mathrm{NH}_{3}$. In summary, the introduction of appropriate doping elements and defects can improve the response of graphene materials to gas molecules.

In 2009, the adsorption capacity and response of gas molecules to aluminum and sulfur doped graphene were further investigated by Dai et al. from National University of Defense Technology [68]. Al-doped graphene was not suitable for the preparation of sensor materials due to its strong reaction to $\mathrm{NO}$ and $\mathrm{NO}_{2}$. N-doped graphene was possibly not reactive enough, while B-doped and S-doped graphene were able to chemically bind $\mathrm{NO}_{2}$ and possibly $\mathrm{NO}$ as well.

In 2012, Masel et al. grown polycrystalline graphene on the surface of polycrystalline copper foil and researched the influence of graphene line defect on the sensitivity of organic gas [69]. Figure 10 compares the response of the original graphene, graphene microstrip, and defective graphene to a $100 \mathrm{~ms}$ pulse of $300 \mathrm{ppb}$ toluene (electron donor) and 1,2-dichlorobenzene (electron acceptor). The original graphene basically did not respond, but the graphene microspheres and defective graphene response is obvious. The linear defects of graphene can improve the gas sensing properties. 


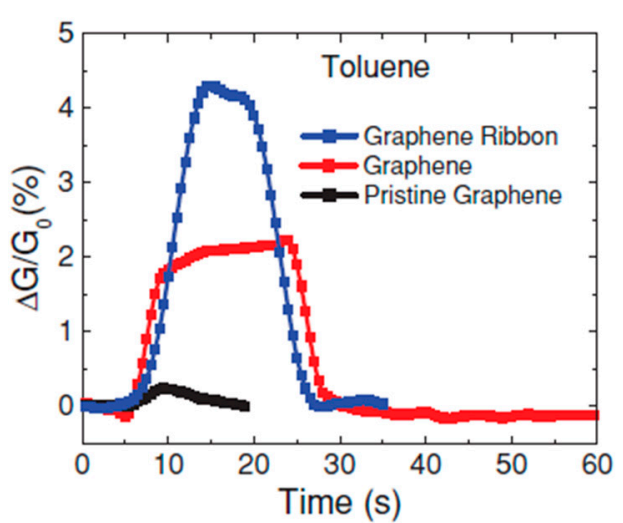

(a)

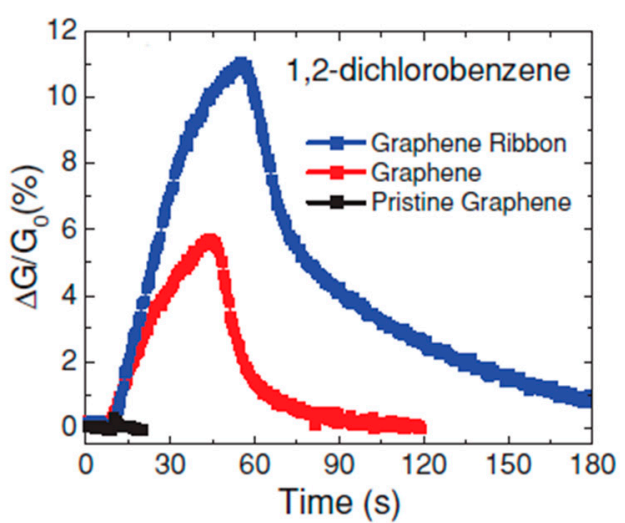

(b)

Figure 10. (a) Ratio of conductance to initial conductance response of CVD-grown defective graphene, CVD graphene microribbon, and $5 \mu \mathrm{m}$ wide pristine (exfoliated) graphene sensors to $10^{14}$ molecules of toluene; and (b) CVD-defective graphene, CVD graphene microstrip and a $5 \mu \mathrm{m}$ conductivity change of $10^{15}$ 1,2-Dichlorobenzene molecules [69].

In 2012, Pingan Hu et al. proposed a method for preparing graphene gas sensors by printing CVD graphene on a silicon wafer to form a regular-shaped graphene silicon wafer and modifying palladium particles on the surface. The sensor produced by this method has good sensing performance [70]. Sun Jinghua et al. (2014) proposed a patent about the preparation method of CO gas sensor based on nitrogen-doped graphene. This method was used to heat the mixture of urea and graphene powder under vacuum conditions, and the Gr-N/Pt electrode with electrocatalytic activity could be prepared at one time. The prepared sensor had significant electrochemical catalytic effect, short response time and good repeatability [71].

Sulfur hexafluoride $\left(\mathrm{SF}_{6}\right)$ is widely used in gas-insulated electrical equipment due to its excellent insulating and arc extinguishing properties. However, partial discharge (PD), which is a common phenomenon during the equipment running processes, causes $\mathrm{SF}_{6}$ to decompose into various products (e.g., $\mathrm{H}_{2} \mathrm{~S}, \mathrm{SO}_{2}, \mathrm{SOF}_{2}$ and $\mathrm{SO}_{2} \mathrm{~F}_{2}$ ). These products may cause equipment failure. Researchers from the University of Texas at Austin investigated the decomposed gaseous components of $\mathrm{SF}_{6}$, namely, $\mathrm{H}_{2} \mathrm{~S}$, $\mathrm{SO}_{2}, \mathrm{SOF}_{2}$, and $\mathrm{SO}_{2} \mathrm{~F}_{2}$, adsorbed on pristine and Au-embedded graphene based on first-principles calculations [72]. Au-graphene showed a more obvious adsorption effect on gas molecules than pristine graphene. The doping of $\mathrm{Au}$ increased the gas sensitivity of graphene because the metal properties of new structure were altered from the zero-gap semiconductor. A large-area monolayer fluorinated graphene $(\mathrm{FG})$ was synthesized using a controllable $\mathrm{SF}_{6}$ plasma treatment by Hui Zhang et al. from Soochow University. It is observed by the Raman spectroscopy that the defects are introduced into the monolayer graphene [73]. The FG based gas sensor exhibited fast response/recovery behavior and high sensitivity that the detection limit of $\mathrm{NH}_{3}$ can reach $2 \mathrm{ppm}$ and the response of $100 \mathrm{ppm} \mathrm{NH}_{3}$ can reach $3.8 \%$ in $30 \mathrm{~s}$ at room temperature.

In 2017, F. Ricciardella et al. from Delft University of Technology contrasted the response of mechanical peel graphene (ME-Gr), CVD prepared graphene (CVD-Gr), and liquid peeling graphene (LPE-Gr) toward $\mathrm{NO}_{2}$ [74], as shown in Figure 11. LPE-Gr (green line) showed no obvious recovery. ME-Gr (black line) showed significant growth after passing gas, and significant decline in the current recovery process. CVD-Gr (red line) trend between the first two. The studies showed that CVD-Gr and LPE-Gr had more obvious defects than ME-Gr. CVD-Gr had many sites on the plane that are prone to gas molecule binding due to its structural diversity. At the same time, LPE-Gr had high energy binding sites, such as defect sites, resulting in its corresponding slow rate. 


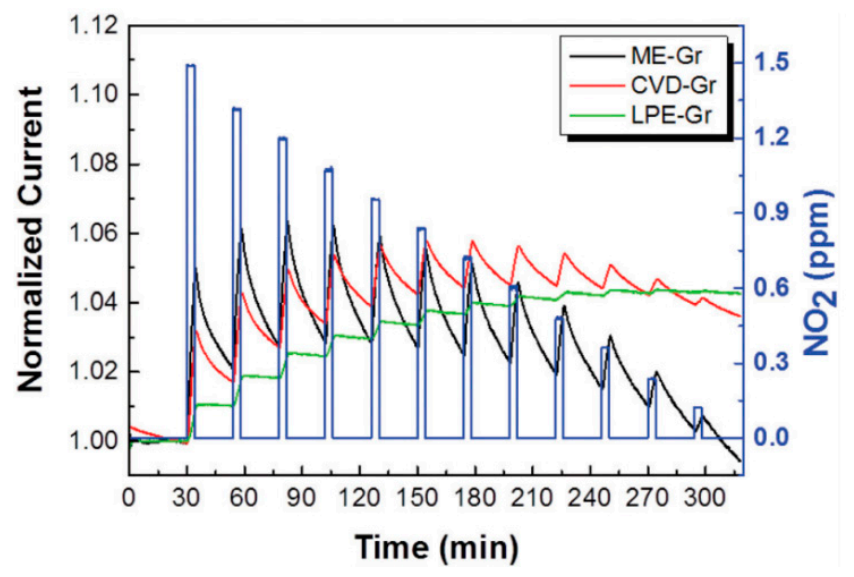

Figure 11. Real-time current behavior of ME-Gr (black line), CVD-Gr (red line) and LPE-Gr (green line) based chemi-resistors upon exposure to sequential $\mathrm{NO}_{2}$ pulses (blue rectangles) at decreasing concentrations from 1.5 down to $0.12 \mathrm{ppm}$. Each exposure step lasts $4 \mathrm{~min}$, preceded and followed by $20 \mathrm{~min}$ long baseline and recovery phases, respectively, in $\mathrm{N}_{2}$ atmosphere. The baseline preceding the first pulse lasts $30 \mathrm{~min}$ in order to allow the device to better stabilize in the test chamber. The current is normalized at the value $\mathrm{I}_{0}$ during the gas inlet of the first pulse exposure [74].

In the process of preparing graphene, defects are inevitable. The initial theoretical study found that defects can enhance the graphene adsorption effect on gas, which aroused widespread concern of researchers [58]. Subsequent experiments also verify this conclusion [60]. Inspired by this, researchers artificially introduced defects into graphene and doped graphene with other elements. The resulting graphene has a very good gas sensitivity and opens up a new gas sensing gap for graphene [63-65].

\subsection{Gas Sensors Based on Graphene/Polymer Composites}

In 2009, Yaping Dan found that photolithography fabrication of graphene devices would inevitably leave polymer photoresist on the graphene surface at a thickness of about $1 \mathrm{~nm}$ [75]. The residue has a significant impact on the device's transmission performance and gas sensing. Figure 12 shows the response of the graphene sensor with polymethylmethacrylate (PMMA) residues to gas with a strong electrical response to ppm-level nonanal vapor before and after the device is washed. These polymers were chemically doped with graphene, and could be used to concentrate gas to improve gas sensing performance. The discovery opened the new dimension of graphene gas sensing field.

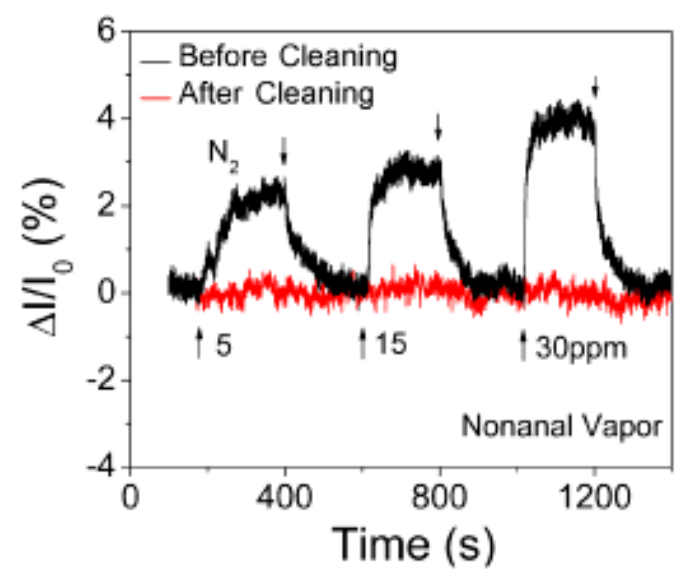

Figure 12. Measured sensor responses, before (black) and after (red) sample cleaning, to vapors of octanoic acid [75]. 
Subsequently, many research groups started the preparation of graphene/polymer composite gas sensors. In 2012, Zhang Li et al. from Tsinghua University prepared a graphene oxide/polypyrene (GO/PPr) polymer and tested gas sensing [76]. The composite exhibited good sensing properties due to its unique structure. The toluene gas showed a fast, linear and reversible response with a sensitivity of $9.87 \times 10^{-4}$.

At the same time, Xiaolu Huang et al. from Shanghai Jiao Tong University demonstrated a practical $\mathrm{NH}_{3}$ gas sensor based on graphene-polyaniline (PANI) hybrids for the first time in 2012 [77]. The combination of graphene and PANI showed positive synergistic effect on ammonia detection that the response was $59.2 \%$ to $50 \mathrm{ppm} \mathrm{NH}_{3}$. The material also showed great response to hydrogen gas, which is reported by Zou Y et al. from Guilin University of Electronic Technology [78]. A $t_{\text {res }}$ of $20 \mathrm{~s}$ and $t_{\text {rec }} 50 \mathrm{~s}$ were obtained when the sensor was exposed to $1 \mathrm{vol} \%$ hydrogen at $25^{\circ} \mathrm{C}$. The large specific surface area of the PANI-GO composite and the catalytic activity of the Pd nanoparticles were the key factors of enhancement of the interaction between the hydrogen molecules and sensing surface led to the improvement in hydrogen-gas-sensing performance.

In 2013, Yanyan Wang et al. from Suzhou University put forward a highly sensitive gas sensor based on graphene/polyaniline hybrid materials [79]. Polyaniline is an organic semiconductor molecule with excellent performance. Its preparation cost is low; the film making process is simple; it is easily compatible with other technologies; and it can work at normal temperature. It has become a hot spot in the research of gas sensors. The combination of graphene and polyaniline can exert the advantages of two performance materials and is of great significance for improving the performance of the sensor. Researchers dispersed graphene/polyaniline hybrid materials in organic solvents; the dispersion was added dropwise Pt electrode surface and dried to obtain the gas sensor. It can be seen in Figure 13 that the response of this composite to $\mathrm{NH}_{3}$ is greatly increased compared to pure graphene, and the resistance change rate can reach $30 \%$.
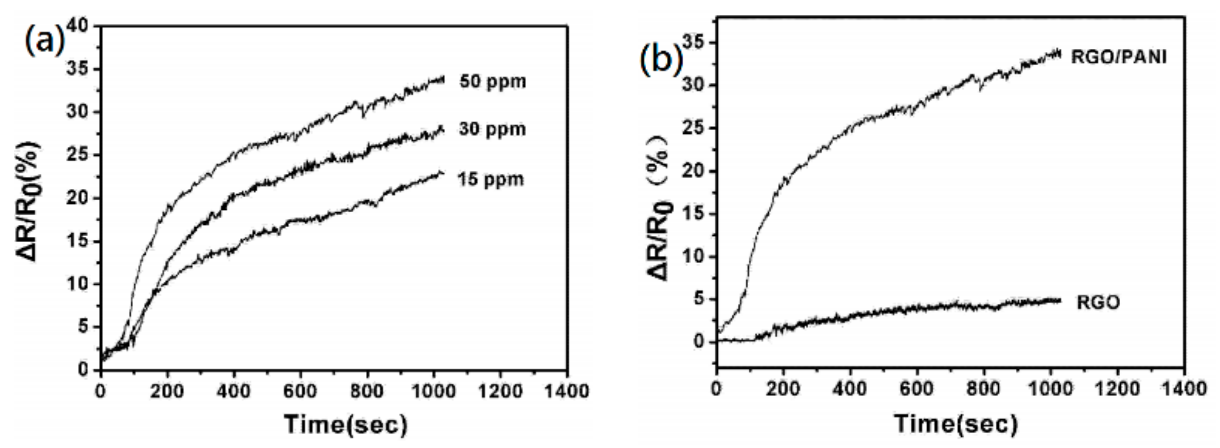

Figure 13. (a) Response curves of gas sensors based on graphene/polyaniline hybrid materials to different concentrations of $\mathrm{NH}_{3}$; and (b) response curves of graphene/polyaniline hybrid materials and conventional redox graphene to $50 \mathrm{ppm} \mathrm{NH}_{3}$ [79].

During the preparation of graphene devices by photolithography, polymer photoresists inevitably remain on the surface of graphene. The composite material has been shown to have important synergistic effects on certain special gases because of its unique selectivity and sensitivity due to the electrical properties. The graphene/polymer composites has been prepared by complexing graphene with polymers and found that these composites have very good gas sensing properties compared to pure graphene, and their sensitivity can reach as high as $30 \%$.

In 2014, Huiling Tai et al. from University of Electronic Science and Technology of China proposed a graphene-based ternary composite film gas sensor and a preparation method thereof [80], as shown in Figure 14. The gas-sensitive material is a composite of graphene, metal or metal oxide nanoparticles and conductive polymer compound. 


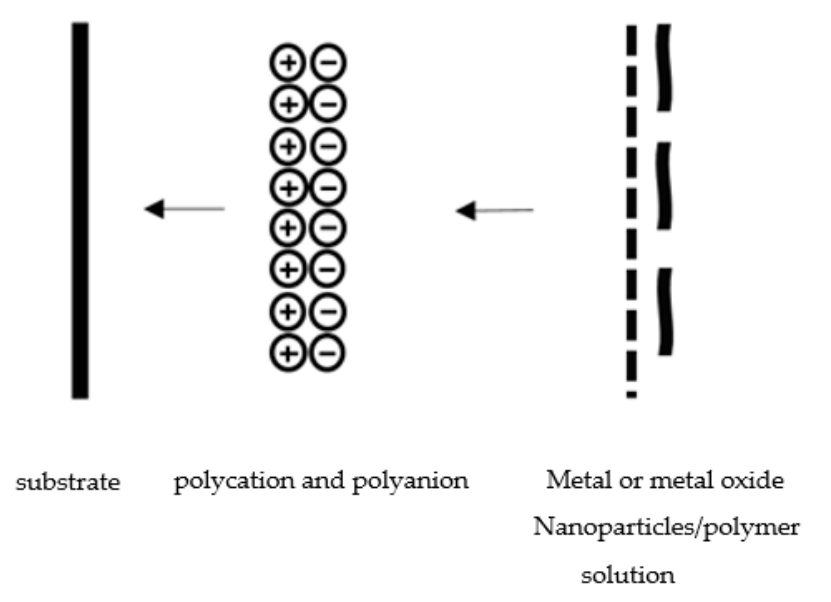

Figure 14. The flow chart of the preparation of ternary composite.

\subsection{Gas Sensors Based on Graphene/Metal or Metal Oxide Composites}

One-dimensional metal oxide nanowires (NWs) or nanorods (NRs), such as $\mathrm{ZnO}, \mathrm{SnO}_{2}$, and $\mathrm{Cu}_{2} \mathrm{O}$, are widely used in the field of sensing due to their high specific surface area, large aspect ratio, and good flexibility [81]. However, these nanostructures have poor electrical conductivity. The combination between metal oxide and two-dimensional graphene can effectively improve electrical conductivity and improve sensing performance.

Doping has been widely used as an effective way to improve the performance of gas sensors. Doping semiconductor oxides with carbon-based materials results in new physical and chemical properties of the resulting composite, while also increasing the sensitivity and selectivity of graphene sensing. At the same time, the metal oxide and graphene doping can also prevent the graphene sheet in the drying process of aggregation, graphene yield and quality will be greatly enhanced.

In 2011, Jaeseok Yi from Hanyang University, South Korea employed CVD-graphene sheets along with thin metal layers as the top electrodes of vertically aligned ZnO NRs (ZnO NRs-Gr/M), and studied the performance of this composite sensor [82]. The ZnO NRs-Gr/M hybrid structure could keep sufficient space between the whole nanowires to ensure rapid delivery of gas, as shown in Figure 15. Moving gas molecules could maximize exposure to the NR surface, making highly sensitive gas sensor devices, so that the test results more accurate. In addition, $\mathrm{ZnO}$ NRs-Gr/M had unique mechanical properties and good light transmittance in the visible spectrum, making it possible to find new applications in the field of flexible machinery or transparent sensors. The device showed rapid response to different concentrations of ethanol vapor, and the response to 10-50 ppm ethanol vapor could reach 9-90.

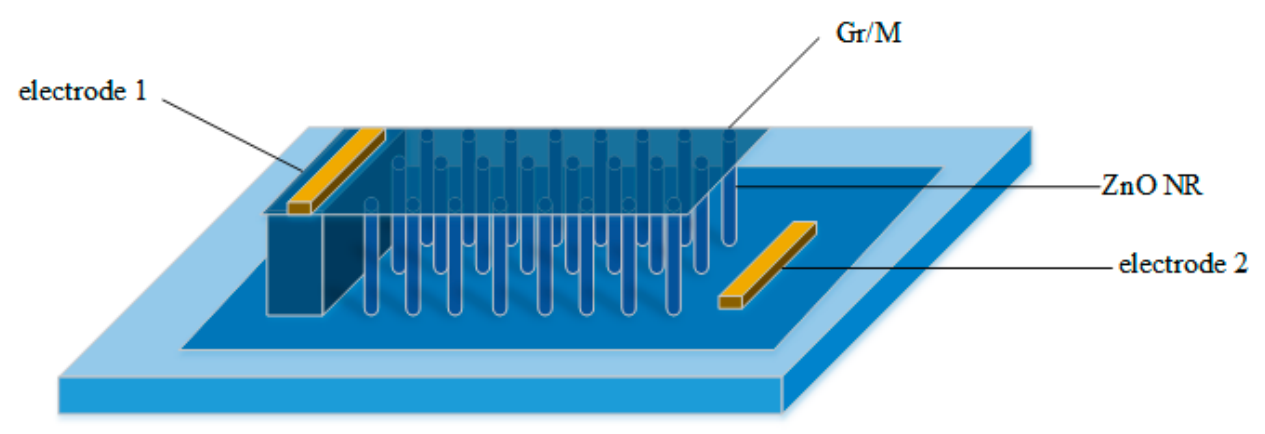

Figure 15. Schematic illustrating of the key steps for fabricating the ZnO NRs-Gr/M hybrid architectures [82]. 
In 2014, Sen Liu et al. from Jilin University synthesized reduced graphene oxide-zinc oxide (rGO-ZnO) nanoparticle composites by redox method [83]. Gas sensitivity tests showed that the response of rGO-ZnO nanoparticle composites gas sensor to $5 \mathrm{ppm}$ of $\mathrm{NO}_{2}$ reaching $25.6 \%$, the response time was $165 \mathrm{~s}$ and the recovery time was $499 \mathrm{~s}$.

In 2014, Wang et al. from Nanjing University of Science and Technology synthesis cupric oxide-zinc oxide/reduced graphene oxide $(\mathrm{CuO}-\mathrm{ZnO} / \mathrm{rGO})$ ternary complex by one-step hydrothermal method [84]. Characterization analysis showed that nanoscale $p-n$ junctions were formed between the $\mathrm{CuO}$ and $\mathrm{ZnO}$ nanoparticles on the $\mathrm{rGO}$. The obtained $\mathrm{CuO}-\mathrm{ZnO} / \mathrm{rGO}$ ternary composite had excellent acetone response (9.4 to $10 \mathrm{ppm}$ ), as shown in Figure 16, almost 1.5 and 2.0 times that of $\mathrm{CuO}-\mathrm{ZnO}$ and $\mathrm{ZnO} / \mathrm{rGO}$, respectively. In addition, ternary composites showed weaker sensing performance on ethanol, which can effectively distinguish between acetone and ethanol. These advantages were attributed to the excellent substrate properties of rGO lamellae and the effective $\mathrm{p}-\mathrm{n}$ junction of $\mathrm{CuO}-\mathrm{ZnO}$.

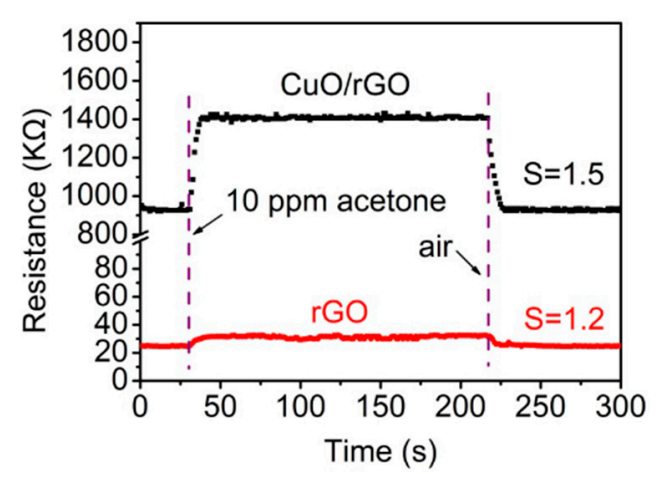

Figure 16. The resistance curves of $\mathrm{CuO} / \mathrm{rGO}$ and pure $\mathrm{rGO}$ sensors to $10 \mathrm{ppm}$ of acetone [84].

In 2015, Singkammo et al. from Chiang Mai University prepared nickel-doped stannic oxide/graphene oxide (Ni-doped $\mathrm{SnO}_{2} / \mathrm{GO}$ ) acetone gas sensor [85]. Gas detection results showed that the acetone response of the $\mathrm{SnO}_{2}$ sensing film was found to be substantially improved, up to 54.2 at $200 \mathrm{ppm}$ and $350{ }^{\circ} \mathrm{C}$ with the lowest Ni-doping level of $0.1 \mathrm{wt} \%$, but further increase of Ni-doping concentration resulted in deteriorated acetone response. In contrast, the acetone response tended to be substantially enhanced with increasing the graphene loading level up to $5 \mathrm{wt} \%$. The graphene-loaded $0.1 \mathrm{wt} \% \mathrm{Ni}$-doped $\mathrm{SnO}_{2}$ sensor exhibited notably high acetone response of 169.7-200 ppm acetone with a short response time of $\sim 5.4 \mathrm{~s}$ at the optimal operating temperature of $350^{\circ} \mathrm{C}$. The enhanced acetone-sensing performances of $\mathrm{Ni}$-doped $\mathrm{SnO}_{2}$ nanoparticles loaded with graphene may be attributed to large specific surface area of the composite structure, specifically high interaction rate between acetone vapor and graphene-Ni-doped $\mathrm{SnO}_{2}$ nanoparticles interfaces and high electronic conductivity of graphene. Therefore, the graphene loaded Ni-doped $\mathrm{SnO}_{2}$ sensor is a promising candidate for fast, sensitive and selective detection of acetone.

In 2015, Huiling Tai et al. from University of Electronic Science and Technology of China proposed a patented graphene/metal oxide composite membrane gas sensor [86]. Metal oxide particles, as a catalytic medium, can reduce the chemical barrier of the electron transfer when the gas molecules are in contact with the graphene, so that enhances the gas sensing properties of the single graphene gas sensing film. Experiments showed that the material's response to $0.5 \mathrm{ppm}$ formaldehyde gas increased from $27.5 \%$ to nearly $40 \%$ compared with a single graphene gas sensor. Gas sensitivity greatly improved.

In 2016, Liu Sen et al. from Jilin University proposed a graphene gas sensor based on $\mathrm{G} / \mathrm{SnO}_{2} / \mathrm{ZnO}$ composite and a preparation method thereof [87]. The gas sensitive material was a three-dimensional porous structure material made of graphene, tin oxide and zinc oxide. The material had a pore size of 3 to $10 \mathrm{~nm}$ and a BET specific surface area of 100 to $230 \mathrm{~m}^{2} / \mathrm{g}$, and 
had good adsorbability to gas molecules. The prepared graphene gas sensor had high and fast response to different concentrations of $\mathrm{NO}_{2}$, the response time wad less than one minute, and had good repeatability.

In 2017, Yang Qu et al. from Huazhong Agricultural University successfully prepared $\mathrm{SnO}_{2}$ nanoparticles coated with graphene oxide nanoplate by hydrothermal method and tested its response to ethanol, acetone and toluene gas [88]. In Table 2, the prepared GO-SnO${ }_{2}$ composite had more porosity and higher specific surface area than the pure $\mathrm{SnO}_{2}$. The increase of specific surface area may be due to the aggregation and ablation of GO particles by GO to form pores, favors gas sensing applications and showed relatively high sensitivity and hence better adsorption of gas molecules. The average pore size of the material was about $10 \mathrm{~nm}$, with small variations in the proportion of doped $\mathrm{SnO}_{2}$. Gas detection showed that $\mathrm{GO}$ as a dopant can significantly increase the gas sensitivity to gases. According to the experimental results, $0.3 \mathrm{wt} \% \mathrm{GO}$ sensor had the best gas sensitivity to ethanol, acetone and formaldehyde. For toluene gas, $1.0 \mathrm{wt} \% \mathrm{GO}_{-} \mathrm{SnO}_{2}$ had the greatest sensitivity.

Table 2. Material data analysis of $\mathrm{GO}-\mathrm{SnO}_{2}$ with different mass fraction [88].

\begin{tabular}{|c|c|c|c|c|c|}
\hline Sample & $\begin{array}{c}\text { GO Mass } \\
\text { Raction (wt \%) }\end{array}$ & $\begin{array}{l}\text { Crystallite } \\
\text { Size (nm) }\end{array}$ & BET $\left(\mathrm{m}^{2} \cdot \mathrm{g}^{-1}\right)$ & Pore Size (nm) & $\begin{array}{l}\text { Pore Volume } \\
\left(\mathrm{cm}^{3} \cdot \mathrm{g}^{-1}\right)\end{array}$ \\
\hline Pristine- $\mathrm{SnO}_{2}$ & 0 & 14.1 & 34.87 & 10.41 & 0.0101 \\
\hline $0.3 \mathrm{GO}-\mathrm{SnO}_{2}$ & 0.3 & 14.9 & 56.58 & 10.73 & 0.0193 \\
\hline $0.5 \mathrm{GO}-\mathrm{SnO}_{2}$ & 0.5 & 14.7 & 59.02 & 10.54 & 0.0177 \\
\hline 1.0GO-SnO & 1 & 14.3 & 61.36 & 10.18 & 0.0192 \\
\hline
\end{tabular}

Recently, Karaduman I et al. from Gazi University synthesized ammonia gas sensors based on rGOdecorated by Ag, Au and Pt nanoparticles (NPs) using a single-step chemical reduction process in 2017 [89]. The responses for $1 \mathrm{ppm} \mathrm{NH} \mathrm{N}_{3}$ were calculated as $6.52 \%, 2.87 \%$ and $0.5 \%$ for AgNPs-rGO, PtNPs-rGO and AuNPs-rGO, respectively. Considering sensitivity, response and recovery time, and LOD, it was observed that AgNPs-rGO sensor exhibited a significant sensing performance for ammonia gas with a low detection at room temperature.

Microwave (MW)-assisted irradiation is an original way for the synthesis of nanomaterials due to its volumetric heating that can eliminate temperature gradient. In 2017, $\mathrm{ZnO}$ /graphene nanocomposites was successfully synthesized by Hyoun WooKim et al. from Hanyang University using MW irradiation [90]. The response of $\mathrm{MW}$ irradiated $\mathrm{ZnO} /$ graphene nanocomposite sensor to $1 \mathrm{ppm} \mathrm{NO} \mathrm{NO}_{2}$ were $12.57 \%$, and for $10 \mathrm{ppm} \mathrm{NO} \mathrm{NO}_{2}$ were $46.42 \%$, which were higher than pristine $\mathrm{ZnO}$ sensor and $\mathrm{ZnO} /$ graphene nanocomposite sensor. It is mainly because the graphene sheets had high surface areas, and active defects at the graphene- $\mathrm{ZnO}$ heterointerfaces and graphene- $\mathrm{ZnO}$ heterojunctions exist on the graphene-ZnO. ZnO NW-rGO nanocomposites also showed excellent response (about 19.2\%), fast response time and full recovery to $\mathrm{NH}_{3}$ at room temperature, which was synthesized by Tao Wang et al. from Shanghai Jiao Tong University in the same year [91]. rGO-ZnO bilayer thin films prepared by facile sol-airbrush technology had $30 \%$ enhancement of $R / R_{0}$ to chloroform vapor compared to pure rGO film due to the improvement of film structure, which was synthesized by Tao Wang et al. from Shanghai Jiao Tong University in 2017 [92]. Bhati V S et al. (2018), from Indian Institute of Technology Jodhpur prepared rGO-loaded Ni-doped $\mathrm{ZnO}$ nanostructures by dropping rGO with different concentration (0-1.5 wt \%) on Ni-doped $\mathrm{ZnO}$ nanostructures. The sensor with the best $\mathrm{rGO}$ concentration of $0.75 \mathrm{wt} \%$ showed the maximum sensing response of $63.8 \%$ for $100 \mathrm{ppm}$ hydrogen at $150^{\circ} \mathrm{C}$ [93].

Titanium dioxide $\left(\mathrm{TiO}_{2}\right)$ is very promising due to its high specific surface, low cost and robustness in chemical/corrosive atmosphere. The hybrids of graphene and $\mathrm{TiO}_{2}$ improved the surface structure and enriched the active adsorption site, which improved the sensing performance to $\mathrm{NH}_{3}$ due to the supporting function of $\mathrm{TiO}_{2}$, as reported by $\mathrm{Ye} \mathrm{Z}$ et al. from University of Electronic Science and Technology of China in 2017 [94]. 


\section{Conclusions}

Improving the sensitivity of the sensor is the main goal of studying gas sensing. The excellent conductivity of graphene as well as the surface-rich and easily modifiable functional groups gives it great advantage as a resistance sensor. Through summarizing the performance parameters of the gas sensor, it can be seen in Table 3 that the main gases detected by the graphene gas sensor are $\mathrm{NO}_{2}$, $\mathrm{NH}_{3}$ and other important industrial gases as well as organic gases such as ethanol and acetone. Pure graphene prepared by various methods generally responds well to gases with concentration below $5 \%$. In recent years, graphene, polymer, metal and metal oxide composite obtained by the new composite materials emerge in the field of gas detection, and the response is up to $30 \%$, which greatly enhances the performance, indicating that graphene composites in the gas sensitive material has a very good potential for development. At the same time, researchers have proposed many different sensors and reduced the production cost, such as vertical structure [55], graphene as a vertical electrode [73] and so on, which is the foundation of the graphene sensor scale production.

Table 3. Typical gas sensors based on graphene materials.

\begin{tabular}{|c|c|c|c|c|c|c|c|}
\hline No. & Material & Target Gas & Sensitivity & LOD & Response Time & Year & Reference \\
\hline 1 & CVD Gr & $\mathrm{H}_{2}$ & - & - & $11.8 \mathrm{~s}$ & 2015 & [60] \\
\hline 2 & MPCVD Gr & $\mathrm{NO}_{2}$ & $1141 \%$ & $785 \mathrm{ppt}$ & $2 \mathrm{~s}$ & 2016 & [61] \\
\hline 3 & CVD Gr & $\mathrm{NO}_{2}$ & $\Delta \mathrm{I} \approx 26 \mathrm{nA}$ & 200 ppm & $67 \mathrm{~s}$ & 2016 & [62] \\
\hline \multirow{2}{*}{4} & \multirow{2}{*}{ CVD Gr } & $\mathrm{NH}_{3}$ & $9.3 \times 10^{-5} \mathrm{ppm}^{-1}$ & $17 \mathrm{ppm}$ & $10 \mathrm{~min}$ & \multirow{2}{*}{2017} & \multirow{2}{*}{ [63] } \\
\hline & & $\mathrm{NO}_{2}$ & $0.024 \mathrm{ppm}^{-1}$ & $0.24 \mathrm{ppm}$ & $10 \mathrm{~min}$ & & \\
\hline 5 & $\mathrm{r}-\mathrm{GO}$ & DMMP & $\Delta \mathrm{R} / \mathrm{R}_{0}>10 \%$ & $50 \mathrm{ppm}$ & $150 \mathrm{~s}$ & 2017 & [64] \\
\hline 6 & CVD Gr & methane & $0.344 \mathrm{~nm} \%^{-1}$ & $3.5 \mathrm{vol} \%$ & $50 \mathrm{~s}$ & 2017 & [65] \\
\hline 7 & CVD Gr & $\mathrm{NH}_{3}$ & $\Delta \mathrm{R} / \mathrm{R}_{0}=4.9 \%$ & $18.8 \mathrm{sccm}$ & $70 \mathrm{~s}$ & 2017 & [66] \\
\hline 8 & F-Gr & $\mathrm{NH}_{3}$ & $\Delta \mathrm{R} / \mathrm{R}_{0}=3.8 \%$ & $2 \mathrm{ppm}$ & $30 \mathrm{~s}$ & 2016 & [73] \\
\hline \multirow{2}{*}{9} & CVD-Gr & \multirow{2}{*}{$\mathrm{NO}_{2}$} & $\Delta \mathrm{I} \approx 0.0025 \mathrm{~A}$ & $0.12 \mathrm{ppm}$ & \multirow{2}{*}{$4 \mathrm{~min}$} & \multirow{2}{*}{2017} & \multirow{2}{*}[74]{} \\
\hline & LPE-Gr & & $\Delta \mathrm{I} \approx 0.0020 \mathrm{~A}$ & $0.45 \mathrm{ppm}$ & & & \\
\hline 11 & Pd-PANI-rGO & $\mathrm{H}_{2}$ & $\Delta \mathrm{R} / \mathrm{R}_{0}=25 \%$ & $1 \mathrm{vol} \%$ & $20 \mathrm{~s}$ & 2016 & [78] \\
\hline 12 & rGO-ZnO & $\mathrm{NO}_{2}$ & $\Delta R / R_{0}=25.6 \%$ & $5 \mathrm{ppm}$ & $165 \mathrm{~s}$ & 2014 & [83] \\
\hline 13 & $\mathrm{CuO}-\mathrm{ZnO} / \mathrm{rGO}$ & acetone & $\mathrm{R}_{\mathrm{g}} / \mathrm{R}_{\mathrm{a}}=1.5$ & $10 \mathrm{ppm}$ & & 2014 & [84] \\
\hline 14 & $\begin{array}{l}\text { Ni-doped } \\
\mathrm{SnO}_{2} / \mathrm{GO}\end{array}$ & acetone & $\Delta \mathrm{G} / \mathrm{G}_{0}=27.5 \%$ & 200 ppm & $5.4 \mathrm{~s}$ & 2015 & [85] \\
\hline \multirow{3}{*}{15} & \multirow{3}{*}{ GO-SnO 2} & ethanol & $\mathrm{R}_{\mathrm{a}} / \mathrm{R}_{\mathrm{t}}=160$ & \multirow{3}{*}{200 ppm } & \multirow{3}{*}{-} & \multirow{3}{*}{2017} & \multirow{3}{*}{ [88] } \\
\hline & & acetone & $R_{a} / R_{t}=200$ & & & & \\
\hline & & formaldehyde & $\mathrm{R}_{\mathrm{a}} / \mathrm{R}_{\mathrm{t}}=91$ & & & & \\
\hline \multirow{3}{*}{16} & AgNPs-rGO & \multirow{3}{*}{$\mathrm{NH}_{3}$} & $\Delta \mathrm{R} / \mathrm{R}_{0}=6.52 \%$ & \multirow{3}{*}{$1 \mathrm{ppm}$} & $70 \mathrm{~s}$ & \multirow{3}{*}{2017} & \multirow{3}{*}{ [89] } \\
\hline & PtNPs-rGO & & $\Delta \mathrm{R} / \mathrm{R}_{0}=2.87 \%$ & & $80 \mathrm{~s}$ & & \\
\hline & AuNPs-rGO & & $\Delta \mathrm{R} / \mathrm{R}_{0}=0.5 \%$ & & $100 \mathrm{~s}$ & & \\
\hline 17 & $\mathrm{ZnO}-\mathrm{Gr}$ & $\mathrm{NO}_{2}$ & $\Delta \mathrm{R} / \mathrm{R}_{0}=12.57 \%$ & $1 \mathrm{ppm}$ & $250 \mathrm{~s}$ & 2017 & [90] \\
\hline 18 & ZnO NW-rGO & $\mathrm{NH}_{3}$ & $\Delta \mathrm{R} / \mathrm{R}_{0}=19.2 \%$ & $50 \mathrm{ppm}$ & $100 \mathrm{~s}$ & 2017 & [91] \\
\hline 19 & ZnO-rGO & $\begin{array}{l}\text { chloroform } \\
\text { vapor }\end{array}$ & $\Delta \mathrm{R} / \mathrm{R}_{0}=1.75 \%$ & $20 \mathrm{ppm}$ & $10 \mathrm{~s}$ & 2017 & [92] \\
\hline 20 & $\mathrm{TiO}_{2}$-rGO & $\mathrm{NH}_{3}$ & $\Delta \mathrm{R} / \mathrm{R}_{0}=1.7$ & $10 \mathrm{ppm}$ & $114 \mathrm{~s}$ & 2017 & [94] \\
\hline
\end{tabular}

\section{Future Perspective}

The future of graphene in the field of gas detection is undoubtedly very broad. Due to the advantages in sensitivity, selectivity and small-size, graphene gas sensors have a good application prospect in industrial and agricultural production, and environmental monitoring. For example, graphene gas sensors can detect the breakdown products of $\mathrm{SF}_{6}$, which is meaningful for gas insulating 
of electrical equipment [63]. However, the current large-scale application of graphene still has difficulties. There are two main bottlenecks. Firstly, there is no method for large-scale preparation of graphene gas sensors. Secondly, graphene needs to be further treated to improve its response sensitivity to specific gases. Judging from the current development trend, the improvement of response time may be from the following aspects: (1) increasing specific surface area by modifying surface and compositing with other nanomaterials specifically; and (2) designing appropriate structure. Improved graphene-based sensitive materials will occupy an important position in the future of gas-sensitive materials and show greater advantages as the research progresses.

Author Contributions: W.T. conducted the review and guide on the content. X.L. wrote the manuscript. W.Y. contributed in discussion and helped search the literature.

Funding: The work was supported by Research Program supported by the National Natural Science Foundation of China (61741406) and National Science Foundation of Ningbo (2016A610030).

Conflicts of Interest: The author declares no conflict of interest.

\section{References}

1. Basu, S.; Bhattacharyya, P. Recent developments on graphene and graphene oxide based solid state gas sensors. Sens. Actuators B Chem. 2012, 173, 1-21. [CrossRef]

2. Varghese, S.S.; Varghese, S.H. Two-Dimensional Materials for Sensing: Graphene and Beyond. Electronics 2015, 4, 651-687. [CrossRef]

3. Zhang, T.; Mubeen, S. Recent progress in carbon nanotube-based gas sensors. Nanotechnology 2008, 19, 332001. [CrossRef] [PubMed]

4. Govardhan, K.; Grace, A.N. Metal/Metal Oxide Doped Semiconductor Based Metal Oxide Gas Sensors-A Review. Sens. Lett. 2016, 14, 741-750. [CrossRef]

5. Korotcenkov, G. Metal oxides for solid-state gas sensors: What determines our choice? Mater. Sci. Eng. B 2007, 139, 1-23. [CrossRef]

6. Mohammadi, M.R.; Fray, D.J. Development of nanocrystalline $\mathrm{TiO}_{2}-\mathrm{Er}_{2} \mathrm{O}_{3}$, and $\mathrm{TiO}_{2}-\mathrm{Ta}_{2} \mathrm{O}_{5}$, thin film gas sensors: Controlling the physical and sensing properties. Sens. Actuators B Chem. 2009, 141, 76-84. [CrossRef]

7. He, Q.; Wu, S.; Yin, Z.; Zhang, H. Graphene-based electronic sensors. Chem. Sci. 2012, 3, $1764-1772$. [CrossRef]

8. Zhang, S.; Shao, Y.; Liao, H.; Engelhard, M.H.; Yin, G.; Lin, Y. Polyelectrolyte-induced reduction of exfoliated graphite oxide: A facile route to synthesis of soluble graphene nanosheets. ACS Nano 2011, 5, 1785-1791. [CrossRef] [PubMed]

9. Falkovsky, L.A. Optical properties of graphene. J. Exp. Theor. Phys. 2008, 115, 012004. [CrossRef]

10. Zhang, X.; Wang, Y. Research and Development of Gas Sensors Based on Nanomaterials. Sens. Microsyst. 2013, 32, 1-5.

11. Wang, T.; Huang, D.; Yang, Z.; Xu, S.; He, G.; Li, X.; Hu, N.; Yin, G.; He, D.; Zhang, L. A Review on Graphene-Based Gas/Vapor Sensors with Unique Properties and Potential Applications. Nano Micro Lett. 2016, 8, 95-119. [CrossRef]

12. Sriyudthsak, M.; Teeramongkolrasasmee, A. Radial basis neural networks for identification of volatile organic compounds. Sens. Actuators B Chem. 2000, 65, 358-360. [CrossRef]

13. Wehling, T.O.; Novoselov, K.S. Molecular doping of graphene. Nano Lett. 2008, 8, 173-177. [CrossRef] [PubMed]

14. Pearce, R.; Iakimov, T. Epitaxially grown graphene based gas sensors for ultra sensitive $\mathrm{NO}_{2}$, detection. Sens. Actuators B Chem. 2010, 155, 451-455. [CrossRef]

15. Sun, F.; Xu, S. Application of Graphene Material in Gas-Sensor. J. South China Norm. Univ. 2013, 6, 93-98.

16. Bouvet, M. Phthalocyanine-based field-effect transistors as gas sensors. Anal. Bioanal. Chem. 2006, 384, 366-373. [CrossRef] [PubMed]

17. Novoselov, K.S.; Geim, A.K. Electric Field Effect in Atomically Thin Carbon Films. Science 2004, 306, 666-669. [CrossRef] [PubMed]

18. Ohno, Y.; Maehashi, K. Chemical and biological sensing applications based on graphene field-effect transistors. Biosens. Bioelectron. 2010, 26, 1727-1730. [CrossRef] [PubMed] 
19. Arsat, R.; Breedon, M. Graphene-like nano-sheets for surface acoustic wave gas sensor applications. Chem. Phys. Lett. 2009, 467, 344-347. [CrossRef]

20. Lee, J.; Kim, J. MEMS-based $\mathrm{NO}_{2}$, gas sensor using $\mathrm{ZnO}$ nano-rods for low-power IoT application. J. Korean Phys. Soc. 2017, 70, 924-928. [CrossRef]

21. Hill, E.W.; Vijayaragahvan, A. Graphene Sensors. IEEE Sens. J. 2011, 11, 3161-3170. [CrossRef]

22. Katsnelson, M.I. Graphene: Carbon in two dimensions. Mater. Today 2007, 10, 20-27. [CrossRef]

23. Tian, W.; Zhang, X. A Review of Graphene on NEMS. Recent Pat. Nanotechnol. 2016, 10, 3-10. [CrossRef] [PubMed]

24. Ji, W.S.; Kitt, A. Transfer of CVD-Grown Monolayer Graphene onto Arbitrary Substrates. ACS Nano 2011, 5, 6916-6924.

25. Li, X.; Cai, W. Evolution of graphene growth on $\mathrm{Ni}$ and $\mathrm{Cu}$ by carbon isotope labeling. Nano Lett. 2009, 9, 4268-4272. [CrossRef] [PubMed]

26. Zheng, Y.; Jian, L.; Peng, Z.; Sun, Z.; Zhu, Y.; Li, L.; Xiang, C.; Loic Samuel, E.; Carter, K.; James, M.T. Toward the Synthesis of Wafer-Scale Single-Crystal Graphene on Copper Foils. ACS Nano 2013, 7, 875.

27. Land, T.A.; Michely, T. STM investigation of single layer graphite structures produced on $\mathrm{Pt}(111)$ by hydrocarbon decomposition. Surf. Sci. 1992, 264, 261-270. [CrossRef]

28. Reina, A.; Jia, X. Large Area, Few-Layer Graphene Films on Arbitrary Substrates by Chemical Vapor Deposition. Nano Lett. 2009, 9, 30-35. [CrossRef] [PubMed]

29. Marchini, S.; Günther, S.; Wintterlin, J. Scanning tunneling microscopy of graphene on Ru(0001). Phys. Rev. B 2007, 76, 075429. [CrossRef]

30. Coraux, J.; N’Diaye, A.T.; Busse, C.; Michely, T. Structural Coherency of Graphene on Ir(111). Nano Lett. 2008, 8, 565-570. [CrossRef] [PubMed]

31. Moriyama, S.; Tsuya, D. Coupled Quantum Dots in a Graphene-Based Two-Dimensional Semimetal. Nano Lett. 2009, 9, 2891-2896. [CrossRef] [PubMed]

32. Somani, P.R.; Somani, S.P. Planer nano-graphenes from camphor by CVD. Chem. Phys. Lett. 2006, 430, 56-59. [CrossRef]

33. Chen, F.; Quan, Q. Electrochemical Gate-Controlled Charge Transport in Graphene in Ionic Liquid and Aqueous Solution. J. Am. Chem. Soc. 2009, 131, 9908-9909. [CrossRef] [PubMed]

34. Li, X.; Cai, W. Large-area synthesis of high-quality and uniform graphene films on copper foils. Science 2009, 324, 1312-1314. [CrossRef] [PubMed]

35. Copel, M.; Reuter, M.C. Surfactants in epitaxial growth. Phys. Phys. Lett. 1989, 63, 632-635. [CrossRef] [PubMed]

36. Borovikov, V.; Zangwill, A. Step-edge instability during epitaxial growth of graphene from SiC(0001). Phys. Rev. B 2009, 80, 121406. [CrossRef]

37. Berger, C.; Song, Z. Ultrathin epitaxial graphite: $2 \mathrm{D}$ electron gas properties and a route toward graphene-based nanoelectronics. J. Phys. Chem. B 2004, 108, 19912-19916. [CrossRef]

38. Zhu, Y.; Murali, S. Graphene and Graphene Oxide: Synthesis, Properties, and Applications. Adv. Mater. 2010, 41, 3906-3924. [CrossRef] [PubMed]

39. Brodie, B.C. On the Atomic Weight of Graphite. Philos. Trans. R. Soc. Lond. 2009, 149, 249-259. [CrossRef]

40. Staudenmaier, L. Verfahren zur Darstellung der Graphitsäure. Eur. J. Inorg. Chem. 2010, 32, 1394-1399.

41. Hirata, M.; Gotou, T. Thin-film particles of graphite oxide 1: High-yield synthesis and flexibility of the particles. Carbon 2004, 42, 2929-2937. [CrossRef]

42. Lee, C.; Wei, X. Measurement of the elastic properties and intrinsic strength of monolayer graphene. Science 2008, 321, 385-388. [CrossRef] [PubMed]

43. Weitz, R.T.; Yacoby, A. Nanomaterials: Graphene rests easy. Nat. Nanotechnol. 2010, 5, 699-700. [CrossRef] [PubMed]

44. Nair, R.R.; Blake, P. Fine structure constant defines visual transparency of graphene. Science 2008, 320, 1308. [CrossRef] [PubMed]

45. Lee, C.; Wei, X. Elastic and frictional properties of graphene. Phys. Status Sol. 2010, 246, 2562-2567. [CrossRef]

46. Frank, I.W.; Tanenbaum, D.M. Mechanical properties of suspended graphene sheets. J. Vac. Sci. Technol. B Microelectron. Nanometer Struct. Process. Meas. Phenom. 2007, 25, 2558-2561. [CrossRef]

47. Morozov, S.V.; Novoselov, K.S. Conferences and Symposia: Electron transport in graphene. Phys. Uspekhi 2008, 51, 744-748. [CrossRef] 
48. Sruti, A.N.; Jagannadham, K. Electrical Conductivity of Graphene Composites with In and In-Ga Alloy. J. Electron. Mater. 2010, 39, 1268-1276. [CrossRef]

49. Balandin, A.A.; Ghosh, S. Superior thermal conductivity of single-layer graphene. Nano Lett. 2008, 8, 902-907. [CrossRef] [PubMed]

50. Stoller, M.D.; Park, S. Graphene-based ultracapacitors. Nano Lett. 2008, 8, 3498-3502. [CrossRef] [PubMed]

51. Nair, R.R.; Blake, P. Universal Dynamic Conductivity and Quantized Visible Opacity of Suspended Graphene. arXiv 2008, arXiv:0803.3718.

52. Kuila, T.; Bose, S. Chemical functionalization of graphene and its applications. Prog. Mater. Sci. 2012, 57, 1061-1105. [CrossRef]

53. Jiang, Y.; Raliya, R. Graphene Oxides in Water: Correlating Morphology and Surface Chemistry with Aggregation Behavior. Environ. Sci. Technol. 2016, 50, 6964-6973. [CrossRef] [PubMed]

54. Jiang, Y.; Raliya, R. Graphene oxides in water: Assessing stability as a function of material and natural organic matter properties. Environ. Sci. Nano 2017, 4, 1484-1493. [CrossRef]

55. Schedin, F.; Novoselov, K.S. Detection of Individual Gas Molecules by Graphene Sensors. Nat. Mater. 2006, 6, 652-655. [CrossRef] [PubMed]

56. Hwang, S.; Lim, J. Chemical vapor sensing properties of graphene based on geometrical evaluation. Curr. Appl. Phys. 2012, 12, 1017-1022. [CrossRef]

57. Chen, C.W.; Hung, S.C. Oxygen sensors made by monolayer graphene under room temperature. Appl. Phys. Lett. 2011, 99, 243502. [CrossRef]

58. Yu, K.; Wang, P. Patterning Vertically Oriented Graphene Sheets for Nanodevice Applications. J. Phys. Chem. Lett. 2011, 2, 537-542. [CrossRef]

59. Yavari, F.; Castillo, E. High sensitivity detection of $\mathrm{NO}_{2}$ and $\mathrm{NH}_{3}$ in air using chemical vapor deposition grown graphene. Appl. Phys. Lett. 2012, 100, 203120. [CrossRef]

60. Dutta, D.; Hazra, A. Performance of a CVD grown graphene-based planar device for a hydrogen gas sensor. Meas. Sci. Technol. 2015, 26, 115104. [CrossRef]

61. Wu, J.; Feng, S. Facile Synthesis of 3D Graphene Flowers for Ultrasensitive and Highly Reversible Gas Sensing. Adv. Funct. Mater. 2016, 26, 7462-7469. [CrossRef]

62. Yun, J.; Lim, Y. Stretchable patterned graphene gas sensor driven by integrated micro-supercapacitor array. Nano Energy 2015, 19, 401-414. [CrossRef]

63. Ricciardella, F.; Vollebregt, S. High sensitive gas sensors realized by a transfer-free process of CVD graphene. In Proceedings of the 2016 IEEE Sensors, Orlando, FL, USA, 30 October-3 November 2016.

64. Wang, Y.; Peng, C. Vertical Response Gas Sensor Based on Three-Dimensional Porous Graphene Ultrathin Film and Its Preparation Method. Patent CN106596654A, 16 April 2017.

65. Wei, W.; Nong, J. Graphene-Based Long-Period Fiber Grating Surface Plasmon Resonance Sensor for High-Sensitivity Gas Sensing. Sensors 2017, 17, 2. [CrossRef] [PubMed]

66. Kim, J.H.; Zhou, Q. Suspended Graphene-Based Gas Sensor with $1 \mathrm{~mW}$ Energy Consumption. Micromachines 2017, 8, 44. [CrossRef]

67. Zhang, Y.H.; Chen, Y.B. Improving gas sensing properties of graphene by introducing dopants and defects: A first-principles study. Nanotechnology 2009, 20, 185504. [CrossRef] [PubMed]

68. Dai, J.; Yuan, J. Gas adsorption on graphene doped with B, N, Al, and S: A theoretical study. Appl. Phys. Lett. 2009, 95, 232105. [CrossRef]

69. Salehikhojin, A.; Esreada, D.; Lin, K.P.; Bae, M.H.; Xiong, F.; Pop, E.; Masel, R.I. Polycrystalline graphene ribbons as chemiresistors. Adv. Mater. 2012, 24, 53-57. [CrossRef] [PubMed]

70. Hu, P.; Zhang, R. A Method of Preparing Graphene Gas Sensor Based on Nanometer Soft Printing Technology. Patent CN102680527A, 23 May 2012.

71. Sun, J.; Pan, Z. A Gas Sensor for CO Concentration Detection. Patent CN104237356A, 24 December 2014.

72. Zhang, X.; Yu, L. First-principles study of SF 6, decomposed gas adsorbed on Au-decorated graphene. Appl. Surf. Sci. 2016, 367, 259-269. [CrossRef]

73. Zhang, H.; Fan, L. Spectroscopic Investigation of Plasma-Fluorinated Monolayer Graphene and Application for Gas Sensing. ACS Appl. Mater. Interfaces 2016, 8, 8652-8661. [CrossRef] [PubMed]

74. Ricciardella, F; Vollebregt, S. Effects of graphene defects on gas sensing properties towards $\mathrm{NO}_{2}$ detection. Nanoscale 2017, 9, 6085-6093. [CrossRef] [PubMed]

75. Lu, Y.; Dan, Y. Intrinsic Response of Graphene Vapor Sensors. Nano Lett. 2009, 9, 1472-1475. 
76. Zhang, L.; Li, C. Electrosynthesis of graphene oxide/polypyrene composite films and their applications for sensing organic vapors. J. Mater. Chem. 2012, 22, 8438-8443. [CrossRef]

77. Huang, X.; Hu, N. Reduced graphene oxide-polyaniline hybrid: Preparation, characterization and its applications for ammonia gas sensing. J. Mater. Chem. 2012, 22, 22488-22495. [CrossRef]

78. Zou, Y.; Wang, Q. Doping composite of polyaniline and reduced graphene oxide with palladium nanoparticles for room-temperature hydrogen-gas sensing. Int. J. Hydrogen Energy 2016, 41, 5396-5404. [CrossRef]

79. Wang, Y.; Peng, C. Gas Sensor Based on Graphene/Polyaniline Hybrid Material and Its Preparation Method. Patent CN102879430A, 16 January 2013.

80. Tai, H.; Ye, Z. Graphene-Based Ternary Composite Film Gas Sensor and Its Preparation Method. Patent CN103926278A, 24 April 2014.

81. Zhang, Z.; Zou, R. Highly aligned $\mathrm{SnO}_{2}$ nanorods on graphene sheets for gas sensors. J. Mater. Chem. 2011, 21, 17360-17365. [CrossRef]

82. Yi, J.; Lee, J.M. Vertically aligned $\mathrm{ZnO}$ nanorods and graphene hybrid architectures for high-sensitive flexible gas sensors. Sens. Actuators B Chem. 2011, 155, 264-269. [CrossRef]

83. Liu, S.; Yu, B. Enhancing $\mathrm{NO}_{2}$, gas sensing performances at room temperature based on reduced graphene oxide-ZnO nanoparticles hybrids. Sens. Actuators B Chem. 2014, 202, 272-278. [CrossRef]

84. Wang, C.; Zhu, J. Reduced graphene oxide decorated with $\mathrm{CuO}-\mathrm{ZnO}$ hetero-junctions: Towards high selective gas-sensing property to acetone. J. Mater. Chem. A 2014, 2, 18635-18643. [CrossRef]

85. Singkammo, S.; Wisitsoraat, A. Electrolytically-exfoliated Graphene-loaded Flame-made Ni-doped $\mathrm{SnO}_{2}$ Composite Film for Acetone Sensing. ACS Appl. Mater. Interfaces 2015, 7, 3077-3092. [CrossRef] [PubMed]

86. Tai, H.; Ye, Z. Graphene/Metal Oxide Composite Membrane Gas Sensor and Preparation Method Thereof. Patent CN105092646A, 25 November 2015.

87. Liu, S.; Wang, Z. A Resistive Gas Sensor Based on Graphene/Tin Dioxide/Zinc Oxide Composite, Its Preparation and Application. Patent CN105891271A, 24 August 2016.

88. Han, M.; Liu, W. Graphene oxide- $\mathrm{SnO}_{2}$, nanocomposite: Synthesis, characterization, and enhanced gas sensing properties. J. Mater. Sci. Mater. Electron. 2017, 28, 16973-16980. [CrossRef]

89. Karaduman, I.; Er, E. Room-temperature ammonia gas sensor based on reduced graphene oxide nanocomposites decorated by Ag, Au and Pt nanoparticles. J. Alloys Compd. 2017, 722, 569-578. [CrossRef]

90. Kim, H.W.; Yong, J.K. Synthesis of zinc oxide semiconductors-graphene nanocomposites by microwave irradiation for application to gas sensors. Sens. Actuators B Chem. 2017, 249, 590-601. [CrossRef]

91. Wang, T.; Sun, Z. Studies on $\mathrm{NH}_{3}$ gas sensing by zinc oxide nanowire-reduced graphene oxide nanocomposites. Sens. Actuators B Chem. 2017, 252, 284-294. [CrossRef]

92. Zhou, Y.; Lin, X. Study on gas sensing of reduced graphene oxide/ZnO thin film at room temperature. Sens. Actuators B Chem. 2017, 240, 870-880. [CrossRef]

93. Bhati, V.S.; Ranwa, S. Improved sensitivity with low limit of detection of hydrogen gas sensor based on rGO loaded Ni doped ZnO nanostructures. ACS Appl. Mater. Interfaces 2018, 10, 11116-11124. [CrossRef] [PubMed]

94. Ye, Z.; Tai, H. Excellent ammonia sensing performance of gas sensor based on graphene/titanium dioxide hybrid with improved morphology. Appl. Surf. Sci. 2017, 419, 84-90. [CrossRef]

(C) 2018 by the authors. Licensee MDPI, Basel, Switzerland. This article is an open access article distributed under the terms and conditions of the Creative Commons Attribution (CC BY) license (http://creativecommons.org/licenses/by/4.0/). 